\title{
Practice and Discussion on Teaching of Agroforestry Equipment 3D Design Based on Maker Education
}

\author{
Yang zidong* ${ }^{*}$ Ni yihua, Yao lijian, Ni zhongjin \\ School of Engineering, Zhe Jiang A\&F University, Linan, China \\ Email address: \\ 21534735@qq.com (Yang zidong), 12872173@qq.com (Ni yihua),873357046@qq.com (Yao lijian), 120409366@qq.com (Ni zhongjin) \\ ${ }^{*}$ Corresponding author
}

\section{To cite this article:}

Yang zidong, Ni yihua, Yao lijian, Ni zhongjin. Practice and Discussion on Teaching of Agroforestry Equipment 3D Design Based on Maker Education. Science Innovation. Vol. 4, No. 3, 2016, pp. 122-126. doi: 10.11648/j.si.20160403.11

Received: April 1, 2016; Accepted: May 16, 2016; Published: May 18, 2016

\begin{abstract}
Based on innovative design education of agroforestry equipment,the 3D design, innovative design and modeling parts of agroforestry equipment run through entire teaching in this paper. By CNC machining centers and 3D printer as a platform, and fused the Maker education in whole education process. Thus the students not only have a virtual innovative design, but also can get real experience of manufacturing process and the products. Building the course teaching model based on Maker education. The innovative design capabilities is foundation of Maker education. Based on business demand for the rapidly capabilities of agroforestry equipment $\mathrm{R} \& \mathrm{D}$ and the law of creative education, the teaching process was broken down to three interconnected modules. The process teaching of theory, practice and agroforestry equipment innovation was designed integration. And the "theory - practice - innovation" teaching mode was also implemented. The task-driven project teaching has taken to implement each project. According to the requirements of Maker education, building a 3D printing service support system of education to enrich agroforestry equipment learning.It can provide practical reference for mechanical engineering education.
\end{abstract}

Keywords: Maker, Maker Education, 3D Design, 3D Printing, Agroforestry Equipment, Creative Education

\section{基于创客教育的农林装备三维设计教学实践与探讨}

\author{
杨自栋, 倪益华, 姚立健, 倪忠进
}

工程学院, 浙江农林大学, 临安, 中国

\section{邮箱}

21534735@qq. com(杨自栋), 12872173@qq. com(倪益华), 873357046@qq.com(姚立健), 120409366@qq. com(倪忠进)

中文摘要: 本文以农林装备三维设计的创新设计教学为基础, 将农林装备零部件的创新设计和建模贯穿在整个教学中。 以数控加工中心和3D打印机为平台, 又将创客教育有机地融合在其中, 使学生不仅有虚拟的创新设计, 还能得到制造 过程的体验和真实的产品, 从而构建了基于创客教育的课程教学模式。创客教育的基础是创新设计能力的培养, 基于 企业对农林装备快速研发能力的需求, 以及创新教育的规律, 将教学过程分解为了三个互相联系的模块, 整个过程将 理论教学、实践、农林装备产品创新三大部分进行一体化的组织设计, 实施了 “理论一实践一创新”一体化的教学模 式, 采取了基于任务驱动的项目教学法实施每个项目的教学。根据创客教育的要求, 构建了3D打印教育服务支持体系, 丰富了农林装备创造的学习形态, 为机械工程专业的创客教育提供了实践参考。

关键词：创客, 创客教育, 三维设计, 3D打印, 农林装备, 创新教育 


\section{1. 引言}

创客概念源于英文单词 “Maker”，意指热衷于创意、 设计、制造的群体。创客教育则是指以培养学习者创新、 创业所需知识、能力、视野以及意志品质方面的教育行为, 以及活动、课程和环境的总和 $[1,2]$ 。一个完整的创客教育, 通常是在一个设计和制造不成为障碍的物理空间内，在玩 中学、学中做的轻松环境中, 匹配成熟的教育理念、师资、 课程和社会资源，让参与者慢慢创造出自己的 “产品”。 因此创客教育, 既要依托蕴含大量创意色彩的课程, 又要 结合各具特色的创客空间制造平台, 开展形式多样的创客 教育 [3]。例如山东淄博教育创客空间的创客结合淄博地方 优势产业——陶瓷, 研制的陶泥土3D打印机, 制作出了中 国陶瓷界前所未见的新器型; 浙江农林大学的农林新装备 创客们, 则用临安特有的竹木材料, 制作出了基于竹木材 料的3D打印机, 加工出了普通竹木加工无法完成的个性化
工艺品; 西安理工大学的航模队, 则以无人机为设计制造 对象，完成了大量富有新意的飞行航模设计与制作。

我们在开展以农林装备创新为主线的创客教育时, 组 建了以机械设计制造及其自动化、农业机械化及其自动化、 木材科学与工程、工业设计等专业学生为主体的跨专业创 客合作社群, 如大学生机械创新协会、大学生工业设计研 究协会、大学生木文化协会等创客社群等, 定期开展了 “农林生态之旅” 的创意实践活动。通过生态之旅创意实 践从构思、设计、工艺、产品、使用、回收等全过程对学 生进行生态文化和创客训练, 并通过生态之旅创意活动实 现了小组协作、基于项目的实践、互助学习、开放式探究 和教育的自组织过程, 同时开展了农林装备三维数字化设 计大赛等开放式创意活动; 构建了专家指导团队、3D打印 支持平台、加工中心等软硬件支撑平台; 营造了竹木创意 产品、现代农林装备等共创空间，从而形成了以农林为特 色、以创意社群为核心、汇集开放资源和群体智慧的创客 教育生态系统，其运行模式和系统结构如图1所示： 创客教育生态系统: 创客社群一>创意活动一 $>$ 工程实训中心一 $>$ 农林生态之旅实践一>创客空间一 $>$ 创客教育

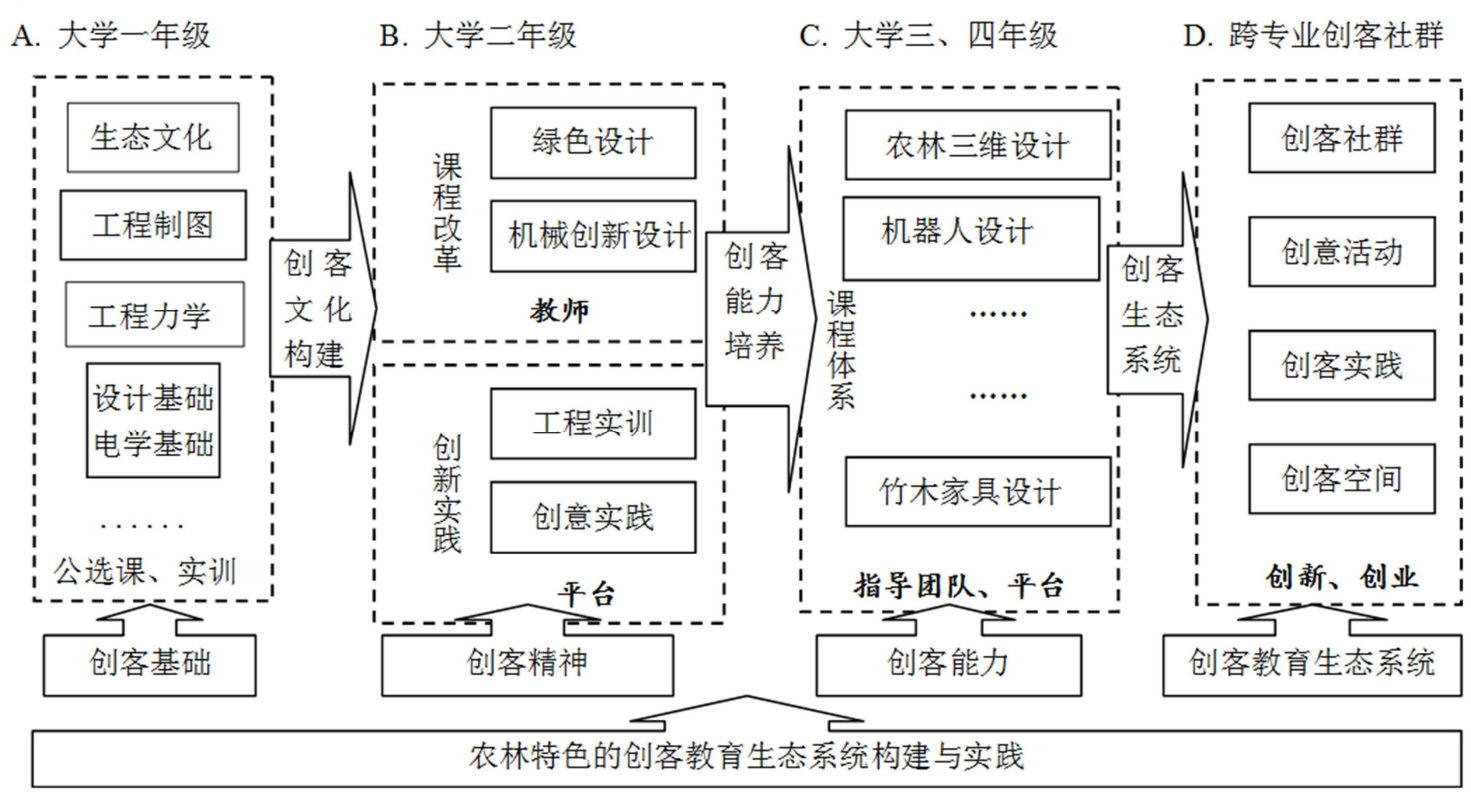

图1 农林装备创客教育生态系统结构示意图。

在开展农林装备三维设计的课程教学中, 一方面将农 林装备零部件的创新设计和建模贯穿在整个教学中, 另一 方面在配备了加工中心和3D打印机后, 又将创客教育有机 地融合在其中，使学生不仅有虚拟的创新设计，还能得到 制造过程的体验和真实的产品, 使创客教育有了实实在在 的依托。

创客教育的基础是创新设计能力的培养。农林装备三 维设计课程以培养教学对象的农林装备产品快速研发能 力和设计能力为重点, 突出农林装备三维建模基本操作的 训练, 结合农林装备种类繁多、创新设计空间巨大的特点, 非常有利于学生创新设计能力的培养。基于企业对农林装 备快速研发能力的需求, 以及创新教育的规律, 我们将教 学过程分解为了三个互相联系的模块, 整个过程将理论教
学、实践、农林装备产品创新三大部分进行一体化的组织 设计, 实施了 “理论一实践一创新”一体化的教学模式, 主要采用基于任务驱动的项目教学法实施每个项目的教 学。各个模块有机衔接, 教学组织过程依次展开。课堂理 论教学、上机实际操作、方案设计讨论、农林装备典型零 部件三维设计、作业展览与评价以及产品制作皆贯穿于整 个教学活动之中。同时, 根据整个课程的课堂教学设计, 在实施以项目教学法为主的专业教学方法时, 灵活选择了 实验教学法、模拟教学法、案例分析教学法、头脑风暴教 学法等方法, 提高了课堂教学效果和学生创新能力的培养。 该课程的课堂教学活动全程在 $\mathrm{CAD} / \mathrm{CAM}$ 机房和实训中 心, 实践教学与理论教学融为一体易于实施 “理论一实践 一创新” 一体化教学, 演示教学与操作训练并重, 交互性 
强, 学生有更多的参与, 学习更为主动, 有助于操作方法 的掌握。并通过3D打印将创意加工成产品的实践操作训练, 非常有利于提高学生学习的积极性和创客精神的培养。

\section{2. 采用项目教学法开展农林装备三维设计的创 新教育}

项目教学法采取将理论知识、操作技能融合到每一个 项目实施中中开展教学。它将复杂丰富的知识点、操作技 能有序地融入到教学内容, 需要设计若干包含不同操作技 能的教学项目, 形成基本知识、专项技术应用技能与综合 实践能力有机结合的三维设计技术的项目教学法教学体 系。运用项目任务教学法, 不仅能很好地调动学生学习的 积极性和自主性, 而且非常有利于教学效果和教学质量的 提高, 其实施流程如下图所示:

其实施流程如图2所示:

(1) 给出典型零部件结构尺寸或设 定产品功能及参数描述

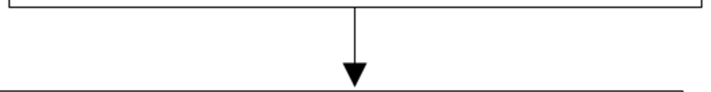

（2）分组讨论，并设计、表现方案

(3) 分析、点评作业, 讲解投影原理和相 关的制图规范，分析作业中存在的问题

(4) 根据相关的要求, 调整或修改设计方 案（完成任务）“教学做一体化”

图2 项目教学法实施流程图。

市场需求是农林产品设计的源泉, 项目载体的选择必 须充分体现市场发展变化, 切实反映农林装备企业生产制 造的实际状况。为此我们在教学前进行了大量的企业调研 活动, 积极参加农林机械展示会、工业设计研讨会和数字 化产品展览会, 为农林装备三维设计教学项目载体的选择 提供了丰富的参考资源。同时教学过程遵循人类认知的基 本规律, 按照由简单到复杂的顺序逐层次推进。在本课程 的项目教学中, 产品3D模型基础设计的项目载体皆选自农 林机械设计中的典型零部件, 如法兰盘、圆盘锯、纹杆和 缺口圆盘耙片等; 高级造型设计的项目载体则来源于典型 的农林装备零部件, 如螺旋输送摚龙、玉米收获机摘穗辊、 勺轮式排种器壳体等。项目实施过程中, 农林产品的造型 设计不仅考虑到了结构、加工工艺的合理可行性, 也要满 足审美、心理等文化需求, 这些综合素质的锻炼对提高学 生的职业技能和创新能力能起到重要作用 $[4,5]$ 。

\section{3. 项目教学法在农林装备三维设计教学的实施 模式}

在项目教学法实施过程中, 依照 “讲练训一体化” 的 教学思路, 根据学生特点, 打破传统的学科知识体系, 不 再围绕知识讲解, 而是以职业活动为导向组织教学, 将技 能项目训练贯穿始终, 项目任务驱动, 穿插讲解涉及到的 相关命令和技能, 边讲边练, 以练为主, 突出能力目标。 “讲练训一体化” 的教学分技能项目训练和技能强化训 练两部分。

技能项目训练安排在了 $\mathrm{CAD} / \mathrm{CAM}$ 机房进行, 四节课连 堂以保证学生有充分且连贯的练习和接受辅导的时间, 充 分让学生动手、动口、动脑。整个教学过程分为六步: “知识讲解 $\rightarrow$ 示范操作 $\rightarrow$ 模仿操作 $\rightarrow$ 变通运用 $\rightarrow$ 复述总 结 $\rightarrow$ 任务考评”。第1节 45 分钟的课程中, 讲解理论 10 分 钟, 实践演示 20 分钟, 学生上机实践模仿操作 15 分钟; 第 2 节45分钟, 教师就学生在模仿操作中出现的问题做相应 的指导, 典型问题集中进行讲解示范; 个别问题单独辅导, 以保证每位学生都能完成教材上的例题。当有学生完成例 题时要求其保存, 教师布置课后题库中与本次课相关的练 习。第 3 节 45 分钟, 学生独立思考, 变通运用完成练习, 教师给予适当的启发式引导。第4节45分钟, 教师根据学 生完成任务的情况进行相关知识及操作要点的复述总结, 并做相应的示范。最后20分钟的时间进行任务考评，逐一 检查每位学生的三维设计模型, 详细登记成绩, 并给予恰 当的评价 $[6,7,8]$ 。设计中出现新的思路, 教师在班上大 力提倡并给予该生加分鼓励; 设计模型完成质量好的, 给 予积极而有效的评价, 通过这种交流, 让学生体验成功的 喜悦, 树立学习的信心。

\section{4. 创新思维的调动和课堂教学效果调控}

\section{1. 利用学生的好奇心激发求知欲望}

我们在讲授农林装备三维设计课时, 每个项目一般事 先准备了十几个采用SolidWorks 开发典型农林装备三维 造型的现实作品展示给学生欣赏, 然后总结本项目的学习 方法, 从而很好地激发了学生的学习兴趣和跃跃欲试的求 知心理。

\section{2. 创造生动活泼的课堂气氛调动学生兴趣}

我们通过采用启发式、讨论式教学方法, 在课堂上充 分发挥学生的群体活动能力。先导学演示, 指导要点, 然 后把学生分成几个项目小组, 围绕实践任务进行实际操作, 放手让学生探究讨论知识, 给学生提供尽可能多的讨论分 析、创造反思的机会, 使学生在知识方面相互补充, 在学 习方法上互相借鉴, 善于合作, 取长补短, 共同进步。例 如在项目五典型农林机械装配体三维设计教学中, 我们将 学生分组, 每个小组成员完成不同的零件图, 最后共同完 成装配体。这种教学法不仅让学生体会到团队配合协同工 作的重要性, 还有利于学生形成新的认知结构和培养自我 学习能力。 


\section{3. 学生层次差异问题的分析及对策}

在实施项目教学法的教学中, 学生的学习态度、思 维能力和对新事物的接受能力不一样, 掌握程度也会出 现层次差异, 学习三维设计课程差异性尤为明显。如何 有效地在教学中缩小差异, 是提高教学质量非常重要的 问题。

人人皆可成才是职业教育首要的理念, 因材施教则是 实现该理念的永恒的教育原则。实施分层教学、分层训练、 先进带动后进的团队学习法等因材施教的教学方法, 通过 对学生的分层教学, 分层练习, 分层辅导, 分层评价, 分 层矫正, 调动学生学习可能性的易变因素, 使教学要求与 学生学习可能性相互适应, 以达到各类学生产生接受效应, 共振效应, 使每一个学生都能在原有基础上获得充分的发 展 $[9,10]$ 。我们在教学内容的安排上, 以中等生为基准, 兼顾 “两头” , 问题的设计考虑不同层次学生的需求, 难 易适中, 具有梯度, 既安排统一授课的内容, 又安排不同 层次的作业训练, 学生共同练习, 教师个别辅导, 从而在 多样化的、开放性的作业训练中培养学生的创造性思维。 开放性的作业设计是分层教学的关键。对学习较困难的学 生只要求做基础的, 带有模仿性的练习; 中上水平学生则 要求做变式的、综合的练习; 基础扎实、认知水平较高的 学生则设计一些有利于发展思维, 拓展能力的题目。对于 同一题目, 也可以有弹性的要求。这样可使每个学生在自 己原有的基础上有所发展, 使不同水平的学生都有题可做, 有新知识可学。这样, 给全班学生都受到必要的能力训练, 达以分层教学的目的。

\section{5. 应用3D打印实施农林装备三维设计课程的创 客教育}

作为一种快速成型技术, 3D打印是蕴含 “设计思维” 的个性化创造工具, 可以塑造可重用的多态教育对象, 打 造虚实结合的教育应用服务创新平台, 促进基于创造的学 习。当前有代表性的3D打印教育创新应用项目, 主要集中 在创客空间、创新实验室和STEAM课程中。在农林装备三 维设计课程教学中, 应用3D打印教育服务支持体系, 可以 丰富农林装备创造的学习样态, 拓展基于创造的学习存在 形式, 成为创客教育不可或缺的元素 [11]。

\section{1. 塑造可重用的多态教育对象}

$3 \mathrm{D}$ 打印作为3D数字制造技术, 体现出的最大特征是精 准、全息地快速成型。结合数字扫描, 3D打印能快速精准 地打印出学生设计的农林装备三维模型。由真实的生活经 验、技术以及工具整合形成的创意, 不仅可以设计蓝图呈 现, 更可以通过3D打印塑造为多态教育对象, 使三维设计 的教育呈现良好的继承性, 即以前学生的产品可直接作为 教具展示给后学者, 从而使创客教育在一个不断继承的基 础上螺旋式甚至跨越式地展开。如图3所示的滚珠轴承是 机械设计中常用的标准件, 通常查阅手册的方式了解其结 构, 学生感受不深刻。通过三维设计, 学生可以构建轴承 的三维模型, 可以在三维设计环境下完成装配、干涉检查、
运动仿真等过程, 得到非常深刻的轴承结构认识。如果学 生的学习仅仅停留在上述过程, 还不是创客教育的本质所 在, 应用3D打印技术, 可以将构建的三维模型转化成实体 模型, 并可装配到机器构建上实现其支撑运动的功能, 整 个从设计到制造再到产品组装的全过程就构成了农林机 械的创客教育过程。
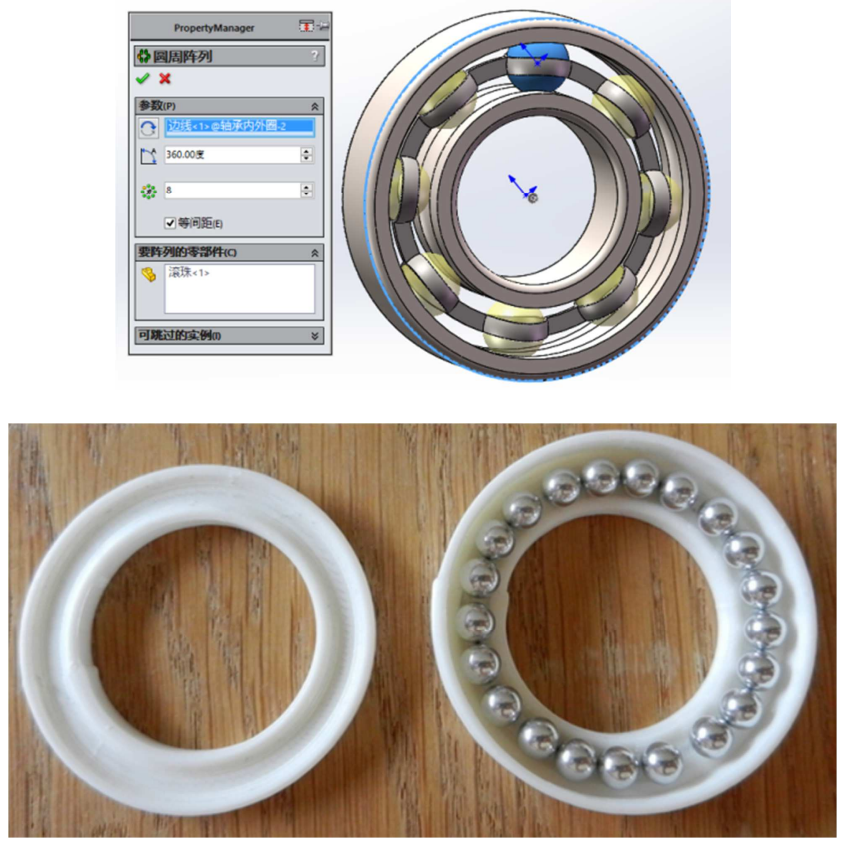

图3 轴承三维建模与3D打印模型。

\section{2. 蕴含 “设计思维” 的个性化创造工具}

3D打印将个性化定制关键的影响因素如技能、成本、 时间都降低到最低点, 不需要增加额外的成本, 不需要掌 握专业的工艺, 就可以打印出复杂、多样化的农林装备构 造体; 不仅实现独立的零部件成型, 更能将所有装配部件 作为整体一次性打印成型。在差异化教育模式探索中, 3D 打印能使不同教育层次的个人以专业水平实现从想象到 产品的个性化创造, 满足学习者对个性化创意设计进阶的 不同需求 [12]。这样, 通过农林装备三维设计课程的训练, 借助3D打印设备平台, 最大限度地促成了机械设计专业的 学习者从教育消费者到创造者的转变。

\section{6. 结束语}

创造是人的本性, 创造是认知、社会和情感活动的重 要组成部分, 具体体现是新颖的独创性想法或行动, 是和 理解、运用社会文化背景知识产生出某种新颖和有价值产 品的创造性思维及活动紧密相连的。基于3D打印的各种农 林装备零部件设计制作中, 通过3D打印塑造的多态教育对 象能够对各种学习策略提供有效的支撑。比如使用3D打印 技术个性化打造的拖拉机车轮、驾驶室造型、机械手模型 等, 可以让学生的想象转换成作品, 抽象农林机械结构转 化为可视化的三维模型绘制, 学习者自然而然完成了创造 者的蜕变。因此应用3D打印创新平台, 可以开辟基于农林 
装备创造的个性化学习空间, 从提出探究问题开始, 到构 建新颖的独创性想法和构思, 最后制造出有社会价值的农 林装备创意产品, 这是一个 “学”与 “做” 的循环迭代过 程, 真正实现了基于三维设计课程的创客教育。

\section{致谢}

本文为浙江省普通本科高校新兴特色专业建设项目 《机械设计制造及其自动化专业》建设及浙江省高等教育 课堂教学改革研究项目《机械制造基础系列课程教学改革 研究》的阶段性成果之一。

\section{参考文献}

[1] (美) 克里斯 - 安德森著, 萧潚译. 创客新工业革命 [M]. 中信 出版社, 2012:9-23。

[2] Bae, T. , J., Qian, S., S., Miao, C., et al. The relation ship between entrepreneurship education and entrepreneurial intentions: Ameta-analytic review [J]. Entrepreneurship Theory and Practice, 2014, (2) : 217-254.

[3] 韩晨光, 曲绍卫, 纪效珲. 能力基点: 理工科大学生创业创 客教育课程设计及实践——基于两岸理工科大学生创业能 力调查数据 $[J]$. 现代教育技术 $2015.02: 116-121$ 。

４4］李小涛, 高海燕,邹佳人, 万昆. “互联网+”背景下的STEAM 教育到创客教育之变迁一一从基于项目的学习到创新能力 的培养 [J]. 远程教育杂志2016. 01:30-38。
[5] 王芗, 黄典贵. 创客空间背景下的大学生创新实践教学的应 对与改进——以理工科大学生为例 $[\mathrm{J}]$. 高教学刊 2015. 21:78-79。

[6] 汪思源, 杨凯悦, 王文标. 创新工程教育的理念与探索一一 面向未来的创客实践 [J]. 航海教育研究, 2015. 04:46-50。

[7] 付志勇. 面向创客教育的众创空间与生态建构 $[\mathrm{J}]$. 现代教 育技术, 2015. 05:22-26。

[8] Peter V B. RPAS (Remotely Piloted Aircraft Systems) Yearbook 2013: The Global Perspective (11th Edition) [M]. Paris, France: Blyenburgh \& Co, 2013. [19]

[9] Yasushi Kitagawa. International Programs Review-UAV Activity in Japan Overview [R]. Utsunomiya, Tochigi Prefecture, Japan: Japan UAV Association, 2005. [20] Peter V. B. UAS (Unmanned Aircaft Systems) Yearbook 2010-2011: the Global Perspective (8th Edition) [M]. Paris, France: Blyenburgh \& Co, 2011.

[10] Huang Y B, et al. Current status and future directions of precision aerial application for site-specific crop management in the USA $[J]$. Computers and Electronics in Agriculture, 2010, 74(1) : 34-38.

[11] Selin K. The superorganism account of human sociality: how and when human groups are like beehives [EB/OL]. [2015-10-28]. http://poseidon01. ssrn. com.

[12] Roalter L Moller A et al. Developing intelligent environments[Z] 2011. 